\title{
EREBEA
}

Revista de Humanidades

y Ciencias Sociales

Núm. 7 (2017), pp. 41-62

ISSN: 0214-0691

\section{DISIDENTES Y REFUGIADOS EN UNA CIUDAD TRADICIONAL de la Edad Moderna: Santiago de Compostela ${ }^{1}$}

RESUMEN

Compostela es conocida como el final del Camino de Santiago, pero era también, en la Edad Moderna, la capital de provincia civil y eclesiástica, sede del tribunal de la Inquisición de Galicia y de una Universidad. Su existencia tranquila era alterada por la presencia de forasteros, peregrinos y viajeros. Bajo apariencia de peregrinos llegaban disidentes religiosos en sus países de origen, "herejes" de diferentes confesiones religiosas que buscaban convertirse al catolicismo, y también numerosos refugiados católicos irlandeses, que huían de un poder protestante. Este artículo estudia su acogida por las instituciones eclesiásticas y la vigilancia por parte de la Inquisición.

Palabras Clave

Santiago de Compostela, peregrinación, protestantes, católicos, irlandeses.
Ofelia Rey Castelao

Universidad de Santiago de Compostela

\section{Abstract}

Compostela is know as the final stop on the Way of Santiago. During the early modern era, it was the capital of the civil and ecclesiastical province, but also both the see of the Inquisition of Galicia and the University. Its peaceful life was shattered by the foreigners, pilgrims and travelers. A few of religious dissidents were coming as down the appearance of pilgrims. They were "heretics" of different confessions who were looking for the conversion to Catholicism. And many Irish catholic refugees who run away from a protestant power. This article focuses on the strategies of acceptance wielded by the ecclesiastical institutions and the vigilance of the Inquisition.

\section{KeYwords}

Santiago de Compostela, pilgrimage, Protestants, Catholics, Irish.

1 Investigación financiada por el proyecto "Culturas urbanas: las ciudades interiores en el Noroeste Ibérico. Dinámicas e impacto en el espacio rural”, Agencia Estatal de Investigación, HAR2015-64014-C3-3-R y financiación de fondos Feder. 



\section{INTRODUCCIÓN}

El nombre de la ciudad de Santiago de Compostela seguramente era uno de los más conocidos de la Corona de Castilla en la Edad Moderna. Sin embargo, esto no se correspondía con el conocimiento real de una ciudad que, si bien fue objeto de numerosas visitas de foráneos por ser un importante lugar de peregrinación, no lo fue de descripciones ni de relatos expresivos de su existencia; a esto se suma la precariedad de las crónicas propias y la brevedad de las referencias que figuran en las historias de Galicia del período moderno. De todos modos, reuniendo fragmentos de unos textos y otros, se deduce la imagen de una ciudad tranquila, sin otras inquietudes que las algaradas de revoltosos estudiantes y sin más amenazas externas que las atribuidas a los peregrinos. Esa imagen no es desmentida por la abundante bibliografía existente sobre la ciudad, aunque los problemas de orden público y social no se han tratado todavía de forma monográfica. Lo que pretendemos en esta ocasión es observar si bajo la mansa superficie de la cotidianeidad compostelana se produjeron tensiones provocadas por individuos incómodos que representasen algún tipo de disidencia -empleando este término en sentido amplio- y cómo respondieron las autoridades ante su presencia y sus acciones.

Debemos tener en cuenta que Compostela era una ciudad pequeña en el contexto castellano, pero fue la mayor de Galicia hasta el último tercio del siglo XVIII. En 1588 tenía 1.544 vecinos, unos seis mil habitantes; a causa de la crisis de fines del XVI y comienzos del XVII se redujo a 1.230 vecinos en 1591 y 1.107 en 1611-1614, en torno a cuatro mil cuatrocientos habitantes. En 1635 se recontaron 1.490 vecinos y la atonía vital compostelana empieza a superarse en la segunda mitad del siglo, cuando creció hasta llegar a 14.862 habitantes en 1708; en 1753 tenía 16.807 -cuatro mil quinientos vecinos-, paralizándose después - 15.582 habitantes en 1787 y 17.400 en $1800^{2}$ - . Dentro de sus murallas y rebasándolas, se alojaba una sociedad tradicional en la que los cambios se producían lentamente; sin duda era intensamente clerical, pero también universitaria y artesanal, y contaba con una oligarquía noble y con una pequeña burguesía administrativa, universitaria y económica ${ }^{3}$. En ese contexto

2 E. Martínez Rodríguez, La población de Santiago de Compostela (1630-1860). Estructuras, coyunturas y comportamientos demográficos. Santiago de Compostela: Universidad, 2014, p. 65-78.

3 J.E. Gelabert, Santiago y la tierra de Santiago de 1500 a 1640. A Coruña: Edicións do Castro, 
estable y seguro comparecieron en los siglos XVII y XVIII dos tipos de visitantes inesperados cuya aparición y recepción es lo que nos interesa en estas páginas: se trataba de individuos procedentes del extranjero, inmigrantes extrańos por sus creencias heréticas, aparentando ser peregrinos o siéndolo sinceramente, o bien grupos, como el de los irlandeses, extranjeros también, pero católicos, cuya diferencia respecto a los otros radicaba en su identidad de refugiados políticos y perseguidos religiosos. La presencia de unos y de otros fue mejor o peor aceptada según su número y "su calidad" y si llegaban para quedarse o estaban en tránsito hacia otros destinos; y fue más o menos visible e importante dependiendo de la situación del conjunto de la población en el momento.

En la recepción y tratamiento del problema, que podía derivar en una alteración de la existencia normal de la ciudad, debe tenerse en cuenta a quién correspondía la vigilancia y el control del orden. En este sentido es muy importante el hecho de que Santiago era una ciudad de señorío del arzobispo y que el regimiento municipal era nombrado y controlado por este y por el cabildo catedralicio, en ausencia del prelado ${ }^{4}$. Desde 1563 se reforzó ese carácter señorial con el traslado de la Real Audiencia de Galicia a A Coruña, a donde se desplazó en gran medida por presión del arzobispo, alejando así al tribunal superior y al gobierno del Reino, lo que reforzaba su autoridad y la de los tribunales del prelado. Por parecidas motivaciones de jurisdicción y poder señorial, el tribunal de la Inquisición no pudo instaurarse en Santiago hasta 1572/1574, siendo después una institución mal aceptada por los poderes de la ciudad. Compostela era, desde el punto de vista de la monarquía, una ciudad que merecía cierta atención, o al menos lo fue hasta mediados del siglo XVII. Por una parte, los peregrinos que entraban en la Península eran motivo de prevención por cuanto las insignias de la peregrinación podían ocultar a peligrosos personajes y, por otra, la existencia de una Universidad, fundada en 1522/26 por el influyente arzobispo Alonso Fonseca III, contribuía a sostener cierto temor al contagio de ideas heréticas. A esa doble desconfianza obedeció que finalmente la Inquisición se instalase en Santiago y no en una ciudad de realengo; por la misma razón, allí se concentró el mayor número de comisarios y familiares inquisitoriales, 25 en la concordia fundacional, 33 en $1641^{5}$.

1982. A. Eiras Roel, "Las elites urbanas de una ciudad tradicional: Santiago de Compostela a mediados del siglo XVIII", en A. Eiras Roel (ed.): La documentación notarial y la Historia. Santiago de Compostela: Universidad, 1984, pp. 117-140, vol. I. P. Saavedra, "El dinamismo socio-económico del principal núcleo urbano de Galicia", en E. Portela Silva (ed.): Historia de la ciudad de Santiago de Compostela, Santiago de Compostela: Universidad, 2003, pp. 225-310.

4 M. López Díaz, Señorio y municipalidad. Concurrencia y conflicto de poderes en la ciudad de Santiago (ss. XVI-XVII). Santiago de Compostela: Universidad, 1997.

5 J. Contreras Contreras, El Santo Oficio de la Inquisición en Galicia, 1560/1700. Poder, sociedad y cultura. Madrid: Akal ediciones, 1982, p. 466. 
No hay duda de que siendo Santiago una ciudad pequeña, pocas de su tamaño se vieron en la situación de tener que recibir a foráneos de condición irregular que buscaban protección en sus ricas instituciones, en especial el arzobispo y el cabildo, aprovechando del modo que fuera, su condición de núcleo de peregrinación y, según esto, de acogida. Se da la circunstancia paradójica de que las peregrinaciones sufrieron en el siglo XVI una fuerte disminución a causa de que una parte de los territorios que las enviaban se pasaron al protestantismo y que cuando los protestantes quisieron volver al catolicismo no buscaron en Compostela su conversión sino en Roma. Así pues, quienes llegaron a Santiago con esa intención o emplearon su paso por la ciudad para convertirse, lo hicieron de modo individual y su número fue siempre escaso, sin comparación posible con las cifras romanas ${ }^{6}$. Por otro lado y en un contexto diferente, ajeno en principio a la peregrinación, la ciudad tuvo que atender a los refugiados procedentes de Irlanda, un contingente no muy numeroso si se confronta con los llegados a A Coruña y a otras ciudades norteñas, pero sí muy característico y significativo por cuanto incluía a un buen número de jefes de clan, pero sobre todo a eclesiásticos, acogidos por aquellas instituciones compostelanas. Entre ambas facetas de la acogida de forasteros y de refugiados se recuentan varios puntos comunes y diferencias evidentes.

\section{LA ACOGIDA DE "HEREJEs"}

A fines del siglo XVI y aún después, persistía la arraigada idea de que el Camino de Santiago favorecía la llegada de foráneos sospechosos. Por ejemplo, Cristóbal Pérez de Herrera en Amparo de pobres (1598), al referirse al Hospital de Burgos, comentaba el paso anual de "ocho o diez mil franceses y gascones y de otras naciones que entran con ocasión de romería por estos reinos sin que se sepa por dónde vuelven a salir, ni a qué vienen, ni si van a sus romerías", llegando durante la guerra de Portugal a entrar más de treinta mil "que se puede considerar cuántos herejes de diferentes sectas vendrían entre ellos" y para evitarlo sugería que se les identificase físicamente, mediante el uso del hábito de peregrino, registrándolos en los diferentes puntos de entrada. Lo mismo decía hacia 1600 el sub-prior Huarte al referirse al paso de Roncesvalles, considerando que los peregrinos eran "desterrados de sus propias tierras" y los hospitales donde se acogían eran "cuevas de ladrones". Y Juan D. Fernández Portocarrero, abad de Villafranca del Bierzo, en el año santo de 1621 denunciaba que no tenían ninguna señal de devoción, que se llevaban las limosnas de los pobres y que esto enriquecía a los enemigos de España ${ }^{7}$.

6 D. Julia, "Pour une géographie européenne du pèlerinage a l'époque moderne et contemporaine", in P. Boutry y D. Julia (ed.): Pèlerins et pèlerinages dans l'Europe Moderne. Roma : École Française de Rome, 2000, pp. 3-126.

7 O. Rey Castelao, “Le Chemin de Saint-Jacques à l'Époque moderne. Une revision”, en Revue d'Histoire de l'Eglise de France, no 224 (2004), pp. 109-130. 
Como demostró Jaime Contreras en su monografía sobre el tribunal inquisitorial de Compostela, fue el miedo al protestantismo lo que ayudó a su asentamiento en 1572/74, ante la sospecha de que allí se ocultasen algunos reconciliados que "después de quitados los hábitos vivían en Galicia convertidos", entre los cuales se mencionaba a ingleses y escoceses que habrían huido nada más saber que la Inquisición abría sus puertas ${ }^{8}$. Lo cierto es que fue un tribunal poco activo -2.203 causas entre 1567 y 1700 , el 4,7\% del total inquisitorial-, y que los casos heréticos no fueron numerosos: el 20,5\% fueron causas contra judaizantes, 3,6\% contra sospechosos de ser mahometanos y $9,6 \%$ de ser luteranos; el resto se componía de procesos por proposiciones $(35,5 \%)$ y por delitos de tipo moral. Obviamente, las acciones judiciales y su punición se desarrollaban en Santiago, pero en su inmensa mayoría eran de fuera de la ciudad ${ }^{9}$. Otra cosa era el peligro específico que se asociaba con la figura nómada y extraña del peregrino. Esta prevención se mantuvo en el tiempo, temiendo que entre los peregrinos, sospechosos permanentes de otras cosas, se colasen individuos peligrosos y probables portadores de contagios heréticos, lo que se hacía más claro en períodos bélicos, cuando, además, podían ser espías o potenciales mercenarios al servicio del enemigo.

Sin embargo, revisando la documentación de las instituciones compostelanas, tanto el regimiento municipal como las de atención religiosa -cabildo catedralicioy asistencial -hospitales, hermandad de la Misericordia-, no parece que hubiese un control estrecho sobre los peregrinos. Sin ser muchos en comparación con otros centros de peregrinación, sí lo eran con respecto al tamaño de la ciudad, en especial entre 1630 y 1660, cuando solo los peregrinos y enfermos extranjeros registrados en el Real Hospital, lugar prioritario para su acogida, fueron más de seis mil, franceses en su mayoría, seguidos de flamencos, portugueses, italianos, alemanes, irlandeses, etc. ${ }^{10}$. A fines del siglo XVII y a lo largo del siglo XVIII su número descendió, pero seguían procediendo sobre todo de la Francia católica, por lo que no constan temores sobre su adscripción religiosa.

Claro está, no es posible saber cuántos eran verdaderos peregrinos y cuántos eran solo trabajadores temporeros, soldados huidos de las armas, aventureros, mendigos, maleantes, etc. Pero lo cierto es que apenas se han localizado casos en los que el culto jacobeo sirviese de tapadera a visitantes peligrosos. Podemos citar la causa que la Real Audiencia de Galicia abrió en 1693 contra José Soller, un

$8 \mathrm{~J}$. Contreras Contreras, El Santo Oficio de la Inquisición en Galicia, 1560/1700. Poder, sociedad y cultura. Madrid: Akal ediciones, 1982, p. 42.

9 Contreras Contreras, op. cit., p. 466.

10 B. Barreiro Mallón y O. Rey Castelao, Pobres, peregrinos y enfermos. La red asistencial gallega en el Antiguo Régimen. Santiago de Compostela-Vigo: ed. Nigratrea, 1998. G. Provost, "Les pélerins accueillis à l'Hospital Real de Saint-Jacques de Compostelle dans la seconde moitié du XVIIe siècle", en Ph. Boutry y D. Julia (eds.): Pèlerins et pélerinages dans l'Europe Moderne. Roma: École Française de Rome, 2000, p. 127. 
peregrino mulato procedente de la isla de Santo Domingo que se hizo pasar por sacerdote y que aprovechó esto para cometer delitos ${ }^{11}$. O el proceso inquisitorial de 1722 contra la pareja compuesta por Ana Benita de Soto y Sosa y Jerónimo Paz Salcedo, alias Cerda y Leyva, que "se fingió caballero del orden de Santiago", pero que era un vecino de la gallega ciudad de Betanzos residente en la villa de Padrón con su mujer; ambos fueron procesados por judaizantes, siendo condenado él a cárcel perpetua y ella a seis meses de prisión ${ }^{12}$.

Sin embargo, cuando recurrimos a la documentación parroquial localizamos bastantes casos en los que la llegada a Santiago con motivo de peregrinación sirvió para lavar expedientes de disidencia religiosa y para integrarse en la sociedad gallega por este medio. Debe recordarse que la monarquía hispánica imponía el catolicismo como condición para la integración y que, en teoría, desde el siglo XV hasta el XIX, solo los católicos podían vivir permanentemente en España, pero no bastaba con ser católico; tampoco bastaba con nacer en Espańa: los conversos judíos y los gitanos son prueba de esto. Diferente era el caso de los vasallos extranjeros del rey-católicos o no- y de los católicos extranjeros no vasallos -por ejemplo, los irlandeses-. Los residentes extranjeros que vivían en Espańa podían obtener la naturalización o nacionalidad si cumplían ciertos requisitos o, de forma excepcional, por concesión del rey se conseguía la igualdad jurídica con los regnícolas. Así pues, la conversión al catolicismo o el matrimonio, o las dos cosas al mismo tiempo, eran un modo para lograr la integración ${ }^{13}$. En Galicia, donde la inmigración fue escasa y poco relevante en los siglos modernos ${ }^{14}$, compuesta por solteros con gran frecuencia y en la mayor parte de los casos, solo como lugar de estancia temporal, esa vía de incorporación se dio sobre todo en Compostela: arribados como peregrinos, se trataba de gentes de las que no se sabe bien para qué o cómo llegaron y que o bien no estaban bautizados -eran de otra religión, por lo general- o bien se sospechaba de que no lo estuvieran, de forma que era preciso repetir la ceremonia para evitar dudas o despejarlas.

Por eso mismo, en Compostela era relativamente frecuente el bautizo de personas adultas, muchos más hombres que mujeres, de la más diversa condición y procedencia $^{15}$. Se trata de pocos casos, si se comparan con otros lugares, pero muy

11 Archivo del Reino de Galicia, Real Audiencia, legajo 26339-13, 1693.

12 Relación de los autos particulares de fee que se han celebrado en la Inquisición de Santiago el dia 21 de septiembre de 1722, Madrid, s.a., s.l.

13 T. Herzog, Vecinos y extranjeros. Hacerse español en la Edad Moderna. Madrid: Alianza, D.L., 2006.

14 O. Rey Castelao, "Los extranjeros en la España Noroccidental durante la Edad Moderna", en B. Villar García y P. Pezzi (eds.): Los extranjeros en la España Moderna. Málaga: Universidad, 2003, vol. II, pp. 23-58. J.A. Salas Auséns, «Inmigrantes en una tierra de emigración: extranjeros en Galicia en la segunda mitad del siglo XVIII», Obradoiro de historia moderna, no 13 (2004), pp. 163-193.

15 O. Rey Castelao, "Parrains et marraines en Galice aux XVI'-XIX" siècle: Le diocèse de SaintJacques-de Compostelle”, en G. Alfani, V. Gourdon y I. Robin (eds.) : Le parrainage en Europe et 
significativos y con un alto componente simbólico ${ }^{16}$. En el registro de bautizados de la parroquia de La Corticela se anotaba este tipo de actos ${ }^{17}$. Las ceremonias se hacían siempre en el cuerpo de la catedral, con una inusitada grandiosidad, explicable desde el punto de vista religioso: suponía la conversión de un infiel o de un hereje. Desde el punto de vista social, se justificaba por el evidente exotismo de bautizar a un adulto o a una adulta, en especial cuanto más raro era su origen o su etnia, de modo que era el propio arzobispo -o su visitador- y no el párroco, quien oficiaba, y los padrinos solían extraerse de entre lo más granado de la sociedad compostelana. Para algunos, el bautizo fue menos solemne porque se trataba de casos dudosos, como en 1607 el de Juan de Viloy "de nación francés de Ibernia, del lugar de Arudine", a quien el arzobispo don Maximiliano de Austria mandó bautizar "por decir que no estaba bautizado según el rito de la Santa Iglesia católica”. Sucedió lo mismo en 1720 con Juan José Francisco O'Sullivan, de trece años, hijo del irlandés Cornelio O'Sullivan, coronel del regimiento de Groures y de su mujer, Isabel Matheus Martins, presumiblemente católicos, pero se desconfió de que lo estuviera y se bautiza sub conditione, siendo su padrino el canónigo José Bermúdez de Mandiá.

Cuanto más tarde, más numerosos fueron los bautizos de protestantes, previamente catequizados e instruidos y habiendo abjurado de sus respectivas militancias religiosas ante el tribunal compostelano de la Inquisición; dado que el bautismo "de su secta" sería válido, se cumplían las ceremonias pero no se les imponía el agua bautismal. Así pues, calvinistas, luteranos y componentes de otras religiones cristianas fueron ingresados en el catolicismo entre un público sorprendido por la rareza de estos $\operatorname{casos}^{18}$ :

Empezando por los calvinistas, en 20 de abril de 1733, se convirtió al catolicismo Miguel, hijo de Juan Hubert y Claudia Betrandi, de 36 años, natural de "San Pedro, República de Ginebra, en donde fue educado en los errores de Calvino y no eché agua por constarme estar legítimamente bautizado"; el arzobispo

en Amérique. Pratiques de longue durée, XVI-XXIe siècles. Berna: Peter Lang, eds., 2015, pp. 69-99.

16 F. Fajardo Spinola, Las conversiones de protestantes en Canarias, siglos XVII y XVIII. Las Palmas: Cabildo Insular de Gran Canaria, 1996. En Canarias unos 335 protestantes se hicieron católicos en ambos siglos para integrarse en la sociedad. Aunque menos, también hubo otros casos relevantes. Véase A. Hamer Flore, "Un acercamiento al estudio de la presencia de elementos protestantes en la España de la ilustración: el caso de las Nuevas Poblaciones de Andalucía”, en Ámbitos: revista de estudios de ciencias sociales y humanidades, $\mathrm{n}^{\circ} 13$ (2005), pp. 91-98.

17 Todos los casos de cristianos que se exponen están en los días correspondientes a los bautizos en Archivo Histórico Diocesano de Santiago (A.H.D.S.), Fondo Parroquial, Santa María de La Corticela, libros 4 y 5 . Otros se irán citando en el texto.

18 Algunos de los casos aquí recogidos los estudiamos brevemente en O. Rey Castelao, "Apadrinar a un pobre en la diócesis de Santiago de Compostela, siglos XVII-XIX", en Ma. J. Pérez Álvarez y M. M. Lobo (coords.), Las respuestas sociales a la pobreza en la Peninsula Ibérica durante la Edad Moderna. León: Universidad, 2014, pp. 209-239. 
lo confirmó al día siguiente. En setiembre de 1740 fue bautizada María Alberta, calvinista, una joven de solo veinte años también apadrinada por gente de rango, Jacobo Busquets y Catalina Gloudina, un matrimonio de "verdaderos católicos". En 25 de enero de 1808 es bautizado sub conditione un joven llamado Manuel Hamair, de Manchester, calvinista, que abjuró en presencia del arzobispo y se catequizó y "su conversión se consideró verdadera y que sería un buen católico", imponiéndosele los nombres de Juan Manuel José, actuando como madrina la viuda María Josefa de Acevedo y como padrino el yerno de esta, el comerciante don Esteban López Urive.

Los luteranos fueron un poco más numerosos. En 11 de julio de 1739 abjuró ante la Inquisición "un adulto luterano, alias Holk", de 27 años, hijo de don Juan y doña María Crasbi, daneses; se le impuso el nombre de Manuel cuando antes se llamaba Juan y fue bautizado "por dudar de su anterior bautismo", siendo apadrinado por don Tomás Ocheri, irlandés, presbítero y capellán en el Hospital Real y por dońa María Ventura de los Ríos. En 1740, el 9 de setiembre, fueron bautizados Manuel y Ana Eustaquia Magdalena, de 49 y 43 años, casados entre sí, procedentes de "Helvetia en Germania", luteranos, que abjuraron y fueron acompañados por su padrino por don Juan Francisco del Valle, canónigo y comendatario del arzobispo, en cuyo nombre actuaba. En 1749 se bautizó "una adulta luterana de edad sesenta años llamada en su secta Juana Glondina Elterhausen, natural de la villa de Maisenham (Maguncia)" casada con un piamontés, siendo el padrino don Juan Kielme. Más raro es el caso de una adulta de 26 años, procedente de Anspach, Alemania, hija de Juan Jorge Maeyer, "de nación judío, la qual había profesado la secta luterana y estuviera casada con Juan Xorge Atmanspag anabaptista o herege rebaptizante", de Baden-Baden, a quien en 11 de setiembre de 1774 se le dio bautismo "absolutamente en virtud de no haverle nunca recibido" y tras abjurar ante la Inquisición. Se nombró María Antonia Margarita -antes era Margarita Mayri-, actuando como padrino don Juan Luis Ińiguez, presbítero, limosnero del arzobispo "y no le advertí la cognación y más obligaciones que como eclesiástico ya sabía". En ese mismo día es bautizada la hija de esta mujer, una niña de seis años, llamada Mariana, ahora convertida en María Josefa Jacoba:

Y se le administré absolute, no obstante haver sido su padre difunto sectario de los rebaptizantes por asegurar su madre y haverse ratificado varias veces delante de algunas personas estaba cierta nunca fuera la nińa bautizada que por mi recivio el de párvulos reparado no tener edad de adultos ni perfecto uso de razón, por lo que no fue catequizada (aunque sabía algunos rudimentos de la fee) todo lo que pasé a hacer como y en la forma dicha en virtud de dictámenes de personas doctas. 
Para este caso, el provisor dio el correspondiente decreto y actuó como padrino don Diego Manuel de Góngora, caudatario del arzobispo y uno de sus capellanes, a quien no se le advirtió la cognación porque se dio por supuesto su conocimiento de la doctrina. En medio de esta conversión se produjo un conflicto jurisdiccional con el párroco al que pertenecía el Hospital Real en el que estaba acogida Margarita y la cárcel en la que estaba su marido. Después de lo cual, el cura de La Corticela dio a la pareja las partidas de casamiento y de velaciones y el de bautismo de la niña, certificadas y "traducidas genuinamente al latín y con el sello del arzobispo mediante eran vagos" 19 .

En 28 de marzo de 1779, fray Juan Antonio Muñoz, lector del convento de Santo Domingo, afirmaba haber instruido en la fe y llevado al tribunal de la Inquisición a don Nicolás José Hemberris, de Gotemborg, Suecia, hijo de padres católicos irlandeses, pero él "hereje luterano, decide espontanearse y abjurar sus errores". El arzobispo ordenó bautizarlo aunque "el interesado creía y afirmaba haberle recibido según el rito católico dentro de los tres días después de nacer por ser esta, según decía, la práctica del país y no usarse entre aquellos herejes de otra forma y materia que la usa la Iglesia romana", pero no pudo demostrarlo y fue bautizado sub conditione y secretamente, dándosele luego confesión y comunión y siendo confirmado el 30 de marzo. En 27 de mayo de 1792, don Enrique Smith, capellán de lenguas del Real Hospital, bautizó condicionadamente a un adulto al que se le dieron los nombres de Tomás Felipe; fue su padrino don Tomás de Serantes, canónigo, "que estaba echo cargo de las obligaciones del bautizado". Antes se llamaba Felipe y era un luterano procedente de Witemberg, Alemania, de 28 ańos, hijo de Felipe Santiago Grosman y de María Ana Grosmeni, de la misma ciudad. En 21 de julio de 1792 lo fue en las mismas condiciones Guillermo, natural de Suiza, sirviendo de padrino don Francisco Javier Mier y Campillo, canónigo tesorero, que le impuso el nombre de Jacobo Guillermo.

De las demás religiones cristianas encontramos casos aislados. Solo aparece una anabaptista: en 1738 se bautizó a una mujer "criada en la secta de los hereges anabaptistas", natural de Holanda, de 28 años, catequizada por el capellán de lengua francesa del Hospital Real, por orden del vicario; una vez que "abjuró en la Santa Inquisición... de los errores de la referida secta”, se le puso María Jacoba, aunque antes se llamaba Petronila Obstreman, actuando como padrino don Vicente Calderón, hijo de los condes de San Juan. El único anglicano registrado en La Corticela fue bautizado el 25 de octubre de 1774, habiendo precedido un despacho del provisor que daba la razón al cura en virtud de la prerrogativa de esta

19 La disputa respondió a que "La madre e hija y su segundo marido Antonio Brun estuvieron mientras se cathequizó su muger en el Hospicio que está en los términos de san Juan Evangelista quien pretendiese el cura de aquella parroquia querer bautizar a los aquí contenidos y por la disputa que tuve con el de San fructuoso sobre que uno estaba en la cárcel”. Todo el caso y las citas del texto están en A.H.D.S, Fondo Parroquial, Santa María de La Corticela, libro 5, folio 123. 
parroquia de bautizar extranjeros. Se trataba de un joven de 23 años, llamado Juan Daniel Conversi y fue bautizado como Jacobo Juan José; era natural de Duhart en Inglaterra e hijo de Daniel Conversi y María Iayeneca:

El qual fuera preso y punido por el tribunal de la Santa Inquisición... sin embargo de nunca haver antes recibido el santo bautismo y mediante estuviera preso en la cárcel por diversos motivos, escandalizara a varias personas con proposiciones denigratorias y heréticas, opuestas a nuestra santa fe y religión católica, a la qual se ha convertido y para probar su seria voluntad concurrieron a examinarle dos frailes y el doctor don Bartolomé Gomez, maestro de pajes del arzobispo...

Se bautizó en presencia de varias personas, saliendo de la cárcel con licencia del alcalde mayor y el permiso del provisor y del cura de Santa Susana y San Fructuoso. El padrino fue don Manuel Gómez, de la familia del arzobispo, "al que advertí la cognación espiritual y más obligaciones" ${ }^{20}$.

Finalmente, en 6 de agosto de 1783, se bautizó "un mozo que dixo ser natural de la ciudad de Boston en la America setentrional", hijo de Ricardo Condom y de Isabel Herling, difuntos, que se llamaba Joseph Condom, de 22,5 años, que había "seguido asta este tiempo la secta de los cuáqueros, de la qual y sus dogmas hizo renuncia solemnemente en el santo Tribunal de la Inquisición", y tenía suficiente instrucción en los misterios de la fe; se le dieron por nombres Salvador José y actuó como padrino don Andrés Rivera, canónigo lectoral.

Sin embargo, los bautizos más impactantes, sin duda, eran los de "moros", todos los cuales se hacían con gran asistencia de público, entre el cual sobresalían los notables locales y las gentes de calidad. En 30 de diciembre de 1604, el visitador de don Maximiliano de Austria bautizó a "un hombre de nación moro", cuyo padrino fue el tesorero Roel, imponiéndosele Jácome como nombre, y el 2 de febrero de 1606 fue bautizado otro con el nombre de Cristóbal, cuyo padrino fue Alonso de Salcedo, alguacil mayor de la ciudad. El ocho de diciembre de 1609, el canónigo Francisco Docampo, secretario del arzobispo, echó las aguas benditas a "un moro que se volvió cristiano", de unos veinte años, natural "de la ciudad de Voloñi, reino de Persia”, apadrinado por el licenciado don Martín Carrillo de Alderete, gobernador del arzobispado, poniéndole por nombre Francisco de Santiago; y en 24 de agosto de 1610 fue bautizado Diego Ruiz, "natural de naturaleza de moros", apadrinado por el mencionado alguacil mayor, Alonso de Salcedo ${ }^{21}$. En el resto del siglo XVII no hubo más casos, pero se recuperaron en el XVIII. 
El 25 de febrero de 1724 recibió el agua otro "de la secta mahometana y natural que dijo de la ciudad de Nazaret tierra de Jerusalén", de 35 años, "catequizado e ynstruido en nuestra santa fee por persona a quien dio comisión el arzobispo"; fue bautizado por el doctor don Juan Lorenzo Rallol, prior de la colegiata aragonesa de Mora, que era provisor del arzobispado, actuando como padrino don Manuel Arroyo Herrero y Esgueva, sobrino y familiar del arzobispo, que le puso por nombres Miguel Bautista Matías Lorenzo, "a presencia de mucho número de personas de mucha calidad y distinción que asistieron a tan religioso y devoto acto y sacramento como dicho adulto con la devida disposición ha recibido"; en marzo, este moro fue confirmado en otra ceremonia actuando como padrino el jesuita Padre Ignacio de Soto ${ }^{22}$. En 1727 y con parecido gentío se bautizó otro mahometano, de 87 años, del "Reyno de Miquiniz" (Fez, Marruecos), al que se puso Juan Francisco Gregorio, apadrinado por el mercader don Gregorio Quintela. En la capilla del Hospital Real se bautizó en 20 de setiembre de 1743 a un joven de unos treinta años, llamado "Amet, de nación africano", de la misma procedencia que el anterior e hijo de "padres infieles y sectarios de Mahoma", apadrinado por don Joaquín del Castillo, administrador de la renta del tabaco en Santiago. Los musulmanes no siempre procedían de territorios árabes.

Se sospechaba que era mahometana, pero en realidad se ignoraba la religión de una mujer que se bautizó el 6 de enero de 1737 "con gran concurso de gente; era una adulta gentil natural que dixo ser de Angola, junto a la provincia de Pernambuco, de la corona de Portugal en Africa y vecina de Lisboa, libre" de la que no se sabía su edad -se le calcularon 46 años-, y se le dio por nombre Rosa Baltasar de Santa María - no en vano se cristianó el día de los Reyes Magos y era negra-, siendo su padrino, por orden del arzobispo, el arcediano doctor don Francisco Antonio de Espinosa, "que fue el que la catequizó". En 31 de octubre de 1749, don Policarpo de Mendoza, vicario general, bautizó personalmente a Girg Beck, alias Hornero, de 23 años, hijo de Asma Beck "cuio apellido en nuestro idioma se interpreta hornero" y de Cadona Mecka, mahometanos, "naturales de Petro Waradino, ciudad de Hungría"; se le puso José como nombre y su padrino fue don José de Goiri, canónigo penitenciario de la catedral compostelana y electo abad de San Isidoro de León, "aviendo sido primero catequizado ... por la persona a quien se dio comisión y todo pasó en público a presencia de mucho número de personas de mucha calidad y distinción... y después que lo recibió con tanta devoción y alegría se alistó por soldado del Regimiento de Infantería de Burgos" ${ }^{23}$. 


\section{LA ACOGIDA DE DISIDENTES CATÓLICOS: LOS REFUGIADOS IRLANDESES}

En la primera parte hemos visto una acogida exhibicionista de todo tipo de "herejes", recibiéndolos en el catolicismo y en la ciudad de Santiago con el mayor boato posible, lo que era fácil porque eran pocos y exóticos. En esta segunda trataremos de ver cómo las mismas instituciones que se ocuparon de esa acogida se comportaron cuando se trató de grupos de cierto tamaño a cuyos componentes no había que bautizar, porque ya lo estaban, sino alojar, mantener e integrar. Ese fue el caso de los irlandeses refugiados en Santiago - una parte de los arribados a Galicia-: baste decir que los civiles también bautizaron a sus hijos nacidos en esta ciudad en el recinto de la catedral, pero no en el altar mayor, sino en el edificio anexo de Santa María de La Corticela, la parroquia de los extranjeros, sin diferencia alguna con cualquier vecino ${ }^{24}$.

Arzobispo y cabildo catedralicio eran también los responsables de la acogida de exiliados que llegaban en grupo y así lo asumieron con respecto a los irlandeses llegados en diferentes oleadas a Compostela huyendo siempre del poder inglés. Desde los años sesenta del siglo XVI a 1583 se recibieron algunos irlandeses perseguidos, pero a título individual. Esta inmigración, extraordinaria en Galicia, es bien conocida, en lo que permite una documentación escasa y discontinua, pero suficiente para afirmar que la recepción de los irlandeses fue vista de muy diferentes $\operatorname{modos}^{25}$. La población general no apreció su condición de refugiados religiosos y menos todavía la de rebeldes políticos amigos de Espańa en tanto que enemigos de Inglaterra, y fieles al catolicismo, que era como los veían las autoridades civiles y eclesiásticas. En los solemnes bautizos de herejes la participación popular era imprescindible para dar publicidad a esos actos, aunque el vecindario compostelano fuese un simple testigo de las ceremonias. También en la recepción de los refugiados irlandeses hubo una parte ceremonial y "festiva", la de la llegada, en la que esa participación popular fue también entusiasta, no en vano el exotismo de los notables irlandeses no iba a la zaga de los extraordinarios personajes que hemos visto antes. Pero ahí finaliza todo parecido en el comportamiento popular: los protagonistas de la primera parte eran pocos y ocuparon lugares discretos e individuales en la ciudad o se fueron a otros destinos, pero los

24 De esto se ocupa C. O’Scea, "Nominación de los irlandeses en España, rechazo y asimilación (1600-1680)", en G. Salinero e I. Testón (eds.): Nombres, un juego de engaños. Nominación, movilidad, y antroponimia, siglos XV-XVIII. Madrid: Casa de Velázquez, 2010, pp 121-138. También, Rey Castelao, "Parrains et marraines", op. cit., pp. 69-99.

25 O. Rey Castelao, "Exiliados irlandeses en Galicia de fines del XVI a mediados del XVII", en A. Mestre Sanchís y E. Giménez López (eds.): Disidencias y exilios en la España Moderna. Alicante: Universidad, 1997, pp. 99-116; "Inmigrantes irlandeses en la Galicia del período moderno", en B. Villar García (ed.): La emigración irlandesa en el siglo XVIII. Málaga: Universidad, 2000, pp. 183205; "Exiliados irlandeses en Santiago de Compostela desde fines del XVI a mediados del XVII", en E. García Hernán y otros (eds.): Irlanda y la monarquía hispánica: Kinsale, 1601-2001. Madrid: Universidad de Alcalá y C.S.I.C, 2002, pp. 89-111. 
de esta otra implicaban la incomodidad de su alojamiento y sobre todo, el coste de su mantenimiento, que se hizo mediante contribuciones aprobadas por los poderes públicos pero aportadas por los pecheros. Las autoridades que representaban a la Corona se ocuparon de la logística y de atender a los irlandeses, aliados y hermanos frente a la monarquía inglesa. En las fases más importantes, la que va de la muerte de Felipe II a la "huida de los condes" de 1607 posterior a la batalla de Kinsale (1602), y la provocada por el exilio de los irlandeses rebeldes como consecuencia de la unificación de Irlanda con Gran Bretaña en 1653, el operativo de acogida fue organizado por mandato del Gobernador Capitán General, lo que implicó en ambos casos un reparto entre ciudades hasta que se buscaron soluciones globales de reorganización enviando a los civiles a Flandes o a otros territorios o facilitando su retorno a Irlanda.

Pero la autoridad del Gobernador estaba en A Coruña y no en Compostela. En esta, la autoridad, como ya se dijo, era el arzobispo quien, con el cabildo catedralicio, controlaba el municipio. Nos interesa por lo tanto, la posición de estos ante la doble identidad de los refugiados, de la que ambas instituciones retuvieron la religiosa. Por su propia naturaleza, Santiago recibió al mayor contingente de eclesiásticos, que fueron aceptados en su calidad de perseguidos religiosos, no hay duda, lo que no obsta para que hubiera prevenciones contra ellos y que la Inquisición actuara en algún caso, o para que cambiase la relación desde el momento en que se abrió el colegio de los irlandeses, ya que este significaba que la presencia irlandesa adquiría un carácter permanente, más acusado desde el que colegio optó por encerrarse paulatinamente en sí mismo para preservar su carácter de escuela de mártires.

Los datos existentes revelan que en general ambas instituciones no solo aceptaron a los refugiados, sino que promovieron la exaltación de su disidencia religiosa hasta presentarlos también en algunas ocasiones como candidatos al martirio. A la postre, es fácil deducir que arzobispo y cabildo repartieron sus responsabilidades con otras instituciones, de modo que los monasterios y conventos compostelanos, masculinos y femeninos, tuvieron que hacerse cargo de los regulares irlandeses. Un caso aparte es el de la Compañía de Jesús, que acabó haciéndose con el control de una parte de la comunidad irlandesa a través del colegio de San Patricio. Esta vinculación no interrumpió, en principio, la colaboración de los primeros con los refugiados, pero acabó enturbiándola.

¿Cómo se sustanció la ayuda del arzobispo y del cabildo compostelanos? En general y en principio de forma positiva, de modo que puede afirmarse que el espacio catedralicio, común a ambas instituciones, les fue propicio y allí disfrutaron de prebendas, ayudas, lugar de culto y de predicación. El arzobispo tenía un instrumento muy útil: el reparto de prebendas entre el episcopado irlandés refugiado en Compostela. El arzobispo don Alonso Velázquez nombró su obispo auxiliar a Thomas Strong, obispo de Ossory, que "venía despojado de su obispado por los 
herejes" y que residió en la ciudad al menos entre 1576 y su muerte en 1601, contando con licencia "para ejercer los autos en esta santa iglesia y arzobispado"; para que cumpliera su función debidamente revestido, el cabildo catedralicio le dio en 1576 y en 1587 dos ricos y completos pontificales ${ }^{26}$, y para resolver su situación económica le aprobó en 1600 el arcedianato de Reina por presentación del arzobispo don Juan de San Clemente ${ }^{27}$. La buena relación del obispo irlandés con los arzobispos compostelanos pro-jesuíticos fue muy útil a su sobrino Thomas Vitus (White) para que este desplegase su actuación en beneficio de los jesuitas irlandeses residentes en el colegio compostelano de la Compañía y de los jóvenes irlandeses que ya desde tiempos de Felipe II estudiaban en Santiago ${ }^{28}$. El arzobispo don Maximiliano de Austria colaboró con los nobles irlandeses exiliados pagando los estudios que sus hijos realizaban en la ciudad; colaboración que se produjo cuando todavía el colegio de irlandeses estaba en embrión y bajo el control de los franciscanos $^{29}$. En 1654 moría en Santiago el arzobispo metropolitano de Caselia (Cashel), don Thomas Valesio (Valoys), después de hacer su testamento; el prelado tenía por bulas de reservación del papa, una pensión sobre el obispado de Cádiz, que fue a parar al colegio compostelano de los irlandeses ${ }^{30}$; su espectacular entierro en la propia catedral compostelana se hizo de común acuerdo entre el arzobispo don Fernando de Andrade y el cabildo en consideración a que era un "glorioso confesor y desterrado de Christo" que había sido "echado por los herejes de su silla, de su domicilio, de su patria, por la confesión de la fe católica" ${ }^{31}$.

26 A. López Ferreiro, Historia de la Santa Apostólica, Metropolitana Iglesia de Santiago. Santiago de Compostela: Seminario Conciliar, 1905, vol. VIII, pp. 291-292.

27 En reunión del cabildo de 17-junio-1600, "se intitula al Reverendísimo don Thomas Strong, obispo osoriense in Regno Hiberniae, arcediano de Reina”, tras presentar el correspondiente título expedido a su favor por don Juan de Sanclemente, arzobispo de Santiago, estando vacante la prebenda por muerte del licenciado Juan Ruiz de Carrión. Archivo de la Catedral de Santiago (A.C.S.), Indiferente General, legajo 0558.

28 E. Rivera Vázquez, Galicia y los jesuitas: sus colegios y enseñanza en los siglos XVI al XVIII. A Coruña: Fundación Barrié de la Maza, 1989, p. 424.

29 A.C.S., Protocolos, legajo 134, "cuentas de fray Juan de Nájera, confesor y capellán de Maximiliano de Austria, arzobispo de Santiago y don Diego Feliz Cidrón, mercader, vecino de la citada ciudad del gasto de los estudiantes hijos de nobles irlandeses que estudian en la citada ciudad", 9-abril-1608. Los estudiantes tenían una ayuda de la Corona que libraba el gobernador, conde de Caracena, a través de un depósito en poder de un mercader de la ciudad. Este último se ocupaba de hacer los pagos al convento franciscano, A.C.S., Protocolos, legajo 130, 8-abril-1606.

30 A.C.S., Protocolos, legajo 193, 9-marzo-1654. Meses después, el padre rector del colegio de los irlandeses de la ciudad de Santiago, Guillermo Salnijero, superior de la misión de Irlanda de la Compañía de Jesús, dio un poder al padre Ignacio Lombardo, residente en Madrid, para que cobrase las "decursas y corridos" de una pensión anual que don Thomas Valoys, arzobispo de Cashel, difunto, tenía por bulas de reservación del papa sobre la sede gaditana (A.C.S. Protocolos, legajo 198, 24-octubre-1654).

31 López Ferreiro, Historia de la Santa Apostólica..., p. 118. 
El cabildo socorrió con cierta generosidad a los "pobres irlandeses" que llegaron a Santiago refugiados tras la derrota de la batalla de Kinsale. Pero la práctica de esta institución fue en todo momento la de conceder limosnas a título individual, sin comprometerse en los programas de acogida promovidos por el Gobernador Capitán General de Galicia desde A Coruña. El cabildo subrayaba en esas ocasiones la condición "pobre" de los irlandeses -lo eran en cuanto que habían llegado sin nada a Galicia-, y el peligro que habían sufrido o que todavía sufrían, en especial aquellos que decidían volver a su tierra. Ese fue el caso del jesuita padre Colman, a quien en 1610 se le dieron por mano del canónigo Alonso López una casulla, el ara y el cáliz que había pedido para predicar el Evangelio en Irlanda "con el evidente peligro de muerte que corre" 32 . También fue el de dos frailes irlandeses acogidos en el convento de San Francisco de Santiago, que retornaron a su país en 1619, para lo cual se mandó al mayordomo de la mesa capitular que les diese veinte ducados de limosna ${ }^{33}$. En 1620 se dio otra orden al mayordomo para hacer llegar al irlandés Juan Conde, cien reales de limosna que facilitaran su retorno ${ }^{34}$; en 1631 concedió doscientos reales, también en concepto de limosna, al padre Tadeo Sullivan, rector del seminario compostelano de San Patricio, ya que tenía en proyecto ir a Irlanda y a otras partes a predicar ${ }^{35}$ y en 1633 se ordenó al mayordomo que entregase treinta y seis reales de limosna al cardenal León para que este a su vez los diese a don Tadeo O'Brenan para ayuda de su viaje de vuelta $^{36}$. En otros casos se trató de ayudas a quienes pasaban por Compostela o residieron allí temporalmente: en 1601 se dieron veinticinco ducados de la limosna ordinaria a Thomas White, por entonces rector del colegio de los Irlandeses de la Universidad de Salamanca ${ }^{37}$; en 1613 se indicó al mayordomo que diese a doña Juana Xiraldina, dama irlandesa, doscientos reales de la limosna ordinaria ${ }^{38}$; en 1623 a David Oreto, veinticuatro reales ${ }^{39}$; en 1627 a Abgodonor O'Flynn y Columbano O'Flynn, caballeros irlandeses, cincuenta reales respectivamente y en ese mismo ańo, se mandó al mayordomo que diese a dos estudiantes irlandeses veinticuatro reales ${ }^{40}$. En 1630, el beneficiado por ese tipo de ayudas fue don Cristóbal Colier, quien recibió treinta reales en una ocasión y cincuenta reales en otra $^{41}$, y en 1633 el mayordomo se ocupó de entregar a don Tadeo O’Brenan, cien

32 A.C.S., Indiferente General, legajo 0561, 17-diciembre-1610.

33 A.C.S., Indiferente General, legajo 0562, 11-octubre-1619.

34 A.C.S., Indiferente General, legajo 0562, 5-junio-1620.

35 A.C.S., Indiferente General, legajo 0564, 12-mayo-1631.

36 A.C.S., Indiferente General, legajo 0565, 14-diciembre-1633.

37 A.C.S., Indiferente General, legajo 0558, 23 -febrero-1601.

38 A.C.S., Indiferente General, legajo 0561, 29-enero-1613. Cita otros casos López Ferreiro, Historia de la Santa Apostólica..., vol. IX, p. 156.

39 A.C.S., Indiferente General, legajo 0563, 16-enero-1623.

40 A.C.S., Indiferente General, legajo 0563, 23-junio-1627 y 2-octubre-1627.

41 A.C.S., Indiferente General, legajo 0564, 13-setiembre-1630 y 27-noviembre-1630. 
reales "para remedio de sus necesidades" ${ }^{2}$. Estas cifras, y otras que aparecen en las cuentas capitulares, se justificaron sin excepción como limosnas y siempre oscilaron en los mismos niveles, pero se deduce que se aplicaba un criterio selectivo para dar más o menos dinero en cada ocasión. En la oleada de refugiados huidos de Cromwell a mediados del XVII, el cabildo volvió a ayudar a los irlandeses siguiendo el mismo patrón que en la ocasión anterior, es decir, dejando claro siempre que se trataba de limosnas específicas a personas concretas, sin establecer cantidades fijas ni estables. Así, entre 1655 y 1660 se dieron diversas e importantes ayudas al obispo de Frens, refugiado en el colegio de San Patricio ${ }^{43}$, y se continuó la política de dar dinero a los clérigos seculares que estaban en Compostela o que pasaban por esta y a los regulares y seculares que volvían a Irlanda a predicar y "otros exercicios contra la herexía" ${ }^{4}$.

El cabildo también dio ayudas al colegio de San Patricio creado en Compostela por impulso de Felipe III. De hecho, ya había colaborado con el colegio de irlandeses de Salamanca con anterioridad a abrirse el de Santiago: así, por ejemplo, en 1603 se ordenó al arcediano Samaniego, mayordomo de la mesa capitular, que diese al padre Ricardo Conway, a cuyo cargo estaba el seminario salmantino, treinta ducados ${ }^{45}$ y en 1609 se dieron trescientos reales a la misma institución a petición de la Congregación del Estado Eclesiástico y del Gobernador, conde de Puńonrostro $^{46}$. Una vez encarrilado el colegio compostelano, las limosnas se dirigieron a este: en 1615 se dio orden al mayordomo para entregar trescientos reales al rector del colegio de los irlandeses para ayudar a su mantenimiento ${ }^{47}$, en 1619, mediante la misma mano, se dieron mil cien reales al padre Tomás Vitus (White), que en aquel momento era rector de ese seminario ${ }^{48}$; en 1627 la cantidad otorgada por medio del mayordomo fue de quinientos reales, también entregados al rector ${ }^{49}$, y en 1633 fueron los encargados del repartimiento de la limosna de Semana Santa quienes le dieron treinta ducados, atendiendo al extremo estado de pobreza de la institución ${ }^{50}$. Entre las donaciones al colegio se cuenta en 1621 una hecha por medio del rector padre White, consistente en una parcela pequeña -en realidad, un corral anejo a unas casas- ${ }^{51}$, quizá para completar las instalaciones del nuevo colegio, que se abrió en una casa vendida por el propio cabildo catedralicio

42 A.C.S., Indiferente General, legajo 0565, 3-octubre-1633.

43 A.C.S., Indiferente General, libros 596 y 597, se le dieron quinientos reales de plata en 19-abril-1655 y mil cien en 1600 .

44 Rey Castelao, "Exiliados irlandeses en Galicia...", p. 114.

45 A.C.S., Indiferente General, legajo 0560, 17-diciembre-1603.

46 A.C.S., Indiferente General, legajo 0561, 24-julio-1609.

47 A.C.S., Indiferente General, legajo 0562, 31-agosto-1615.

48 A.C.S., Indiferente General, legajo 0562, 21-febrero-1619.

49 A.C.S., Indiferente General, legajo 0563, 31-agosto-1627.

50 A.C.S., Indiferente General, legajo 0565, 22-marzo-1633.

51 A.C.S., Indiferente General, legajo 0563, 27-marzo-1621. 
después de que el Gobernador ordenase darles un lugar digno; se supone que esta autoridad aportó el dinero para ello ${ }^{52}$. Indirectamente, el cabildo ayudaba al colegio mediante los salarios pagados a los irlandeses que actuaban como lenguajeros o intérpretes de los peregrinos extranjeros en la catedral, es decir, el colegio se encargaba de poner a los lenguajeros que los confesaban y atendían; hacia 1618, cabildo y arzobispo pagaban al colegio mil reales al año para el sustento de uno de esos intérpretes, cifra que aumentó en 1619 gracias a una dotación testamentaria que la fijó en dos mil doscientos reales. Aunque hubo diferencias sobre el lugar donde debían confesar los jesuitas de San Patricio, esa situación se mantuvo hasta la expulsión de la Compañía de Jesús y el cierre del colegio ${ }^{53}$.

No obstante, como decíamos, desde 1611 y en especial desde 1613, el colegio de los irlandeses quedó en manos de los jesuitas y esto supeditó la colaboración del arzobispo y del cabildo a las relaciones que ambas instituciones tuvieran en cada momento con la Compañía de Jesús, muy oscilantes y con períodos serios de conflicto ${ }^{54}$. Tanto el arzobispo como el cabildo colaboraron con los irlandeses mientras se mantuvo su imagen de perseguidos religiosos y a esa imagen solo respondió el colegio de San Patricio a partir de un determinado momento: prueba de eso es que los notables irlandeses residentes en Compostela se opusieron a que se convirtiese en una especie de seminario, cuando ellos estaban interesados en una educación civil para que sus hijos pudiesen integrarse y hacer carrera en la monarquía hispánica, y no solo religiosa, para plebeyos destinados a prepararse como sacerdotes y predicadores que deberían volver a Irlanda a hacer misiones y mantener la fe católica viva. No hay constancia de que arzobispos y cabildo se implicasen en esas luchas internas entre conceptos sociales e identitarios del exilio irlandés que fueron comunes a otras ciudades ${ }^{55}$. Victoriosa la orientación religiosa, el colegio se cerró sobre sí por pura necesidad de mantener las esencias de ese objetivo y para que los estudiantes no se distrajesen de esa finalidad: la selección e ingreso dependían del superior de la Misión irlandesa, tenían que estar formados ya en latinidad, cursaban artes o filosofía en Santiago en el colegio de la Compañía y no en la Universidad. La Compañía impidió que el colegio irlandés tuvie-

52 En 19 de mayo de 1623 el cabildo ordenó una casa de la rúa Nova al colegio de los irlandeses y que los gastos de reparo corran por su cuenta, A.C.S., Indiferente General, legajo 0563. En 23 de marzo de 1626, se mandó al arcediano don Alonso López de Liceras que pagase a Francisco González de Araújo, maestro de obras de la catedral, noventa ducados que recibió de los padres irlandeses por el precio en que se les vendió la mitad de la casa de la rúa Nova donde edificaron su seminario, A.C.S., Indiferente General, legajo 0563.

53 Rivera Vázquez, Galicia y los jesuitas, p. 481.

54 Nos ocupamos de este suceso en O. Rey Castelao, "Los jesuitas y las tradiciones jacobeas: de Mariana a Tolrá”, en J. Martínez Millán, H. Pizarro y E. Jiménez (comps.): Los jesuitas. Religión, politica y educación, siglos XVI-XVIII. Madrid: Universidad de Comillas, 2012, pp. 1249-1280.

55 P. O'Oconnell, The Irish College at Alcalá de Henares 1649-1785. Dublin: Four Courts Press, 1997. 
ra capilla propia y que los estudiantes predicasen o hiciesen misiones pastorales en Galicia. Tampoco tenían biblioteca propia ni contacto con los demás estudiantes. Así pues, los colegiales no mantenían una relación con la Universidad ni con su propio entorno, hasta el punto de no llegar a dominar el castellano ${ }^{56}$. Y a los que se mantuvieron fuera de ese ámbito, no siempre les fue bien.

Si antes decíamos que la Inquisición estuvo atenta a lo que pudieran hacer los irlandeses, no podemos sustraernos al extraño caso del bachiller y maestro de gramática Patricio Synot, irlandés nacido en "Huesfordia”, llegado con sus padres "caballeros irlandeses que habían sido perseguidos por su fe". En 1595 opositó a una cátedra en la universidad compostelana, que no consiguió; años después aparece en A Coruña como asesor del Gobernador conde de Caracena para temas de Irlanda, al tiempo que servía a sus compatriotas como informador y como preceptor de los hijos del clan O'Sullivan Beare; en realidad era uno de los titulares de la cátedra de gramática existente en aquella ciudad, pero en 1606 ya residía en Santiago, cobrando, mediante el tesorero de las alcabalas de Santiago, una renta pagada por la justicia y regimiento de A Coruña ${ }^{57}$. Esta renta se le atribuyó por privilegio real y el hecho de que no ejerciera en A Coruña, sino que vivía en Compostela, quizá se debía a que los O’Sullivan pasaron a vivir en esta ciudad. En 1608 residía en la villa de Noia como preceptor y volvió en ese año a concursar a una cátedra universitaria, fracasando de nuevo. En 1611 consiguió su objetivo en una oposición que dio ocasión a incidentes diversos que lo indujeron a elevar una denuncia ante el claustro toda vez que "los estudiantes eran tan inquietos y que no daban lugar a que se echase de ver lo que cada uno sabía de los que estaban opuestos a la dicha regencia”, denuncia que no deja lugar a dudas de la prevención contra él y de la defensa de los candidatos más afines que propiciaba el sistema de acceso a las cátedras, en manos del claustro y este de los colegiales de Fonseca. Quizá esta misma forma de entrar en la plaza, sin el acuerdo de una parte del claustro, explica que su andadura universitaria fuese también muy azarosa y controvertida; los estudiantes aprovecharon en 1612 su cambio de métodos docentes para denunciarlo, ordenándole el claustro que no impartiese clases por el Arte de

56 O'Connell, The Irish College at Santiago de Compostela, 1605-1769. Dublin: Four Court Press, 2007; Rivera Vázquez, Galicia y los jesuitas, p. 421.

57 "Carta de pago otorgada por el bachiller Patricio Sinote y el bachiller Francisco de Seoane, catedráticos de la cátedra de gramática de la ciudad de A Coruña, estantes en Santiago, en nombre de la justicia y regimiento de la dicha ciudad de A Coruña, a Nicolás de la Torre, tesorero de las alcabalas de Santiago, quien les entregó ciento cuarenta y nueve reales del pago de la renta del año de 1605 del juro que tiene la dicha cátedra 9 de agosto de 1606" (A.C.S., Protocolos, legajo 131, folio 706). "Carta de pago otorgada por el bachiller Patricio Sinote y el bachiller Francisco de Seoane, catedráticos de la cátedra de gramática de A Coruña, estantes en Santiago, en nombre de la justicia y regimiento de la dicha ciudad de A Coruña, a Nicolás de la Torre, tesorero de las alcabalas de Santiago, quien les entregó veinte mil maravedís por la renta del año de 1604 que la dicha cátedra tiene por privilegio real" (A.C.S., Protocolos, legajo 131, folio 707). 
Nebrija sino por el "método de Bravo", y en posteriores ocasiones su presencia entre el profesorado volvió a ser objeto de conflictos, lo que si no era extraño en otros casos de profesores de la tierra, en el caso del irlandés parecen haber sido más frecuentes y problemáticos. Esto se ha atribuido a que no respondía a los métodos convencionales, a sus reiteradas aspiraciones a cátedras de mayor prestigio, a sus peticiones de que se le incrementase el salario, o a su absentismo, como si este no fuera un defecto general del profesorado ${ }^{58}$. No obstante, el irlandés tuvo algunos momentos positivos, como en 1619, cuando se le encargó una pieza teatral. Todo indica que la trayectoria de Patricio Synot, teniendo puntos comunes con otros docentes universitarios, estuvo viciada de origen por su condición irlandesa; el ambiente siempre le fue muy hostil, lo que le impidió hacer carrera en las cátedras compostelanas, le acarreó su exclusión prolongando deliberadamente las vacantías y sustituciones de plazas a las que se presentó, y le granjeó las alteraciones a que daban lugar los concursos en los que participó.

Pero sobre todo, lo que incomodaba a la Universidad y a otros sectores eran ciertas actividades que el irlandés desarrollaba en la ciudad, lo que le supuso un proceso inquisitorial en 1622 cuando fue acusado por prácticas nigrománticas. Si bien no hay pruebas de que las denuncias salieran de los componentes del ámbito universitario, lo cierto es que el juicio terminó definitivamente con su carrera. Synot fue encarcelado en las cárceles de la Inquisición y luego procesado por motivos muy graves: los testigos denunciaron que era "astrólogo judiciario", que hacía adivinaciones mediante la observación de los planetas y la lectura de "los libros de los grandes nigromantes", y que practicaba sortilegios para una clientela que no era numerosa, lo que quizá le valió para que no aparecieran muchos testigos. A pesar de la gravedad de los delitos, el proceso finalizó con su confesión y abjuración, y con un castigo "suave" consistente en una reprensión verbal y en una condena a destierro por dos años; en esta sentencia se tuvo en cuenta que el procesado reconoció todas las acusaciones y que el tribunal de la Inquisición consideró "por ser de la calidad que es y muy pobre" y por respeto a la institución universitaria, no se le incluyó en el auto de fe del 24 de mayo de 1622, sino que un mes antes el claustro permitió a Synot, previa petición suya, irse de Compostela; no volvió a relacionarse con la Universidad, aunque permaneció en Galicia. Uno de los hechos más sorprendentes de este proceso es que los testigos acusaron a Synot de haber robado diversas cantidades de dinero al arzobispo en el palacio de este y, sin embargo, don Beltrán de Guevara no aparece en ningún momento como denunciante; al contrario, no es descartable que la intervención del prelado aligerase la pena de Synot para evitar mayor escándalo. En todo caso, con Synot tenemos la paradoja de un representante cualificado de una familia perseguida en

58 S. Cabeza de León, Historia de la Universidad de Santiago. Santiago de Compostela: Universidad, 1956, vol. II, pp. 257-258, 428, 448. 
Irlanda y que, asentado en otra ajena y supuestamente afín, le fue hostil en el foro peor de los posibles, el inquisitorial ${ }^{59}$.

Otro irlandés sufrió años más tarde la acción de la Inquisición, en este caso por un escrito que molestó mucho al arzobispo y al cabildo compostelanos. Eso es lo que sucedió a Diego Vitus, un jesuita irlandés que había entrado en el colegio de Salamanca en 1680, que luego se graduó en la Universidad de Santiago, y que desde 1696 era profesor de teología en Compostela. Vitus publicó de forma anónima un folleto de dos docenas de páginas titulado Manifiesto del más prudente obrar ${ }^{60}$, que no lleva impresor y figura impreso en Lyón en 1707, donde explicaba de modo polémico la posición de los jesuitas en el delicado tema de si el jubileo servía para conmutar votos privados no reservados, una cuestión sobre la que la Compañía se pronunciaba en contra, pero nunca de modo tan claro como en el texto del irlandés. Por esta razón, el cabildo lo denunció ante Felipe $\mathrm{V}$ y ante las otras iglesias de España, además de pedir su retirada a la Inquisición; el provincial jesuita decidió aplacarlo denunciando también el folleto a ese tribunal, prometiendo castigar a quien lo hubiera escrito. Así pues, la Inquisición prohibió el texto en junio de 1708 y cuando se supo que Vitus era su autor, el provincial lo privó de su cátedra y lo envió a Valladolid, donde murió en 1722. El General Tamburini escribió en junio de 1708 al arzobispo fray Antonio Monroy pidiendo perdón, lo que no puso final al conflicto. De nuevo nos hallamos con la naturaleza extranjera de la única víctima en una lucha de poder entre instituciones, ya que los demás implicados no se vieron afectados por la Inquisición ${ }^{61}$.

\section{Conclusiones}

La condición de núcleo de peregrinación que caracterizaba a Santiago de Compostela, es un elemento que vincula a los dos tipos de foráneos llegados allí buscando acogida y ayuda para su integración. Respondiendo en cierta medida a las sospechas de las autoridades civiles y eclesiásticas y del tribunal de la Inquisición, algunos llegaron a la ciudad como peregrinos y se convirtieron al catolicismo de modo más o menos sincero; las instituciones compostelanas, en especial el arzobispo y el cabildo catedralicio, los utilizaron de forma consciente para hacer impresionantes ceremonias de bautismo después de breves períodos de adoctri-

59 El proceso es relatado por B. Barreiro de Vázquez Varela, Brujos y astrólogos de la Inquisición de Galicia. A Coruña: La Voz de Galicia, 1885, p. 5. Las consecuencias en la Universidad pueden verse en S. Cabeza de León, Historia de la Universidad, vol. II, p. 189, y O’Connell, The Irish College at Santiago, p. 67.

60 Manifiesto del más prudente obrar por el Collegio de la compañia de Jesús de Santiago, y relación de las demostraciones executadas por el Cabildo de la Iglesia del Señor Santiago, contra el dicho Collegio, s.i., Lyon 1707.

61 Rivera Vázquez, Galicia y los jesuitas, pp. 558-560 y sobre todo, M. González Fernández: El idioma de la razón. Ilustración e Inquisición en Galicia. Vigo: Nigratrea, 2008, pp. 127-130. 
namiento religioso. En esos actos se les cambiaron sus nombres imponiéndoles con frecuencia otros con relacionados con el Apóstol Santiago -Jácome, Diego, Jacobo-, incluso si eran de procedencia islámica, lo que no dejaba de resultar irónico en ceremonias que se celebraban bajo la imagen ecuestre del Santiago Matamoros. El elemento jacobeo fue utilizado por el otro grupo, el de los irlandeses como vínculo supuestamente histórico entre Compostela e Irlanda, a través de la predicación del Apóstol en aquella isla, como sostenía la tradición y defendía en su obra Felipe O'Sullivan Beare, profesor en el colegio de los irlandeses de Santiago y autor de una Historia Catholicae Iberniae Compendium (Lisboa, 1621), que se considera un hito en la historiografía irlandesa. Una bibliografía de exaltación pro-irlandesa ha llegado a afirmar que Santiago fue "la verdadera capital del pueblo irlandés exiliado y de los que en su país luchaban por la independencia de su patria" ${ }^{2}$, pero, como hemos visto, esto es matizable desde todos los puntos de vista.

En las dos partes de este artículo tratamos de ver dos procesos distintos, como hemos subrayado a lo largo del texto, aunque complementarios, en los que la disidencia ajena fue recibida con entusiasmo en un caso, como obligación en el otro, sirviendo ambos para la exaltación católica en una ciudad que simbolizaba la expansión del cristianismo en sus primeros tiempos. Los puntos comunes a los dos procesos son esencialmente, tres. El primero es el religioso: en un caso, el de los herejes convertidos, quizá de forma puramente utilitaria, y en el otro, el de los irlandeses, consciente, militante, con una fuerte identidad y con un componente político. El segundo es la importancia del espacio simbólico, situado dentro de la catedral compostelana, escenario de ceremonias de integración de unos y de otros, aunque de modo diferente, como hemos visto. El tercero es la función que los clérigos irlandeses, jesuitas en especial, cumplieron como conexión entre ambos grupos extranjeros y la sociedad compostelana, ya que desde su asentamiento en Santiago, los irlandeses actuaron como intérpretes de peregrinos en el Hospital Real y en los confesionarios de la catedral. Pero el trato dado a los dos grupos fue diferente, si bien en todo momento se mantuvo una política que enfatizaba el carácter excepcional e individual de la acogida y su condición caritativa, de limosna moral o material dada como merecimiento, con un componente heroico o martirial entre quienes la recibían.

62 E. González López, Siempre de negro. Galicia en la Contrarreforma. Vigo: ed. Galaxia, 1970, p. 68. 